\title{
Study on the development strategy of Rural Ecotourism based on Ecological Civilization
}

\author{
Zhang Junying \\ Tourism College of Qinghai NationalitiesUniversity, XiNing 810007,China
}

Key words: ecological civilization; rural eco-tourism; sustainable development

\begin{abstract}
The effective combination of ecological civilization and rural eco-tourism is a reflection of China's sustainable development. The development of rural eco-tourism industry and the protection of resources and environment are contrary. The sustainable development of rural tourism and ecological civilization complement each other, the two are closely related to each other, and promote each other. It is the highest form of eco-tourism development. This paper first introduces the importance of the development of ecological civilization, and then in-depth analysis on the existing problems of rural ecotourism development, and put forward the development strategies of rural eco-tourism in the perspective of ecological civilization, which has a certain significance to promote ecological civilization and sustainable development of rural tourism industry.
\end{abstract}

\section{Introduction}

The meaning of ecological civilization has risen to a new level of harmony between man and nature in "18th CPC National Congress", the ecological environment has been vigorously promoted to a new height. The rural tourism industry is the main content of the development of ecological civilization and town economy, which has the advantages of strong system, long industrial chain, low waste of resources, environmental destruction and so on, it is a resource-saving industry. It is helpful for the sustainable development of tourism and the environment to combine the ecological civilization and the rural eco-tourism. It is a vivid interpretation and practice of modern ecological civilization.

\section{The importance of ecological civilization development}

Ecological civilization refers to the sum of human resource development and resource sharing and to ensure the integrity of the ecosystem, on the basis of the harmonious development of human, nature and society, in the practice of adaptation and transformation of the social environment.

The goal of building ecological civilization and the development of the current environment is consistent, which is the inevitable requirement of harmonious coexistence between man and nature. Ecological civilization is a new form of human civilization. It is a new concept of civilization that developed from the environmental destruction to the common development and environment. Ecological civilization is based on the idea of protect the environment under the strong green development pattern as the main body, with the idea of justice for the purpose, the construction of ecological civilization and low-carbon, green environmental protection technology combined with scientific production mode to ensure the humane and ecological environment development. Looking from the direction of the development of human and nature, ecological civilization is put forward from the side of the severity of China's environmental protection urgency and the destruction of the environment, it also shows the ecological consciousness and improve our national attention on environmental issues. The connotation of ecological civilization is mainly reflected in the cultural 
value, mode of production, life style and social structure. The ecological civilization structure is shown in figure 1.

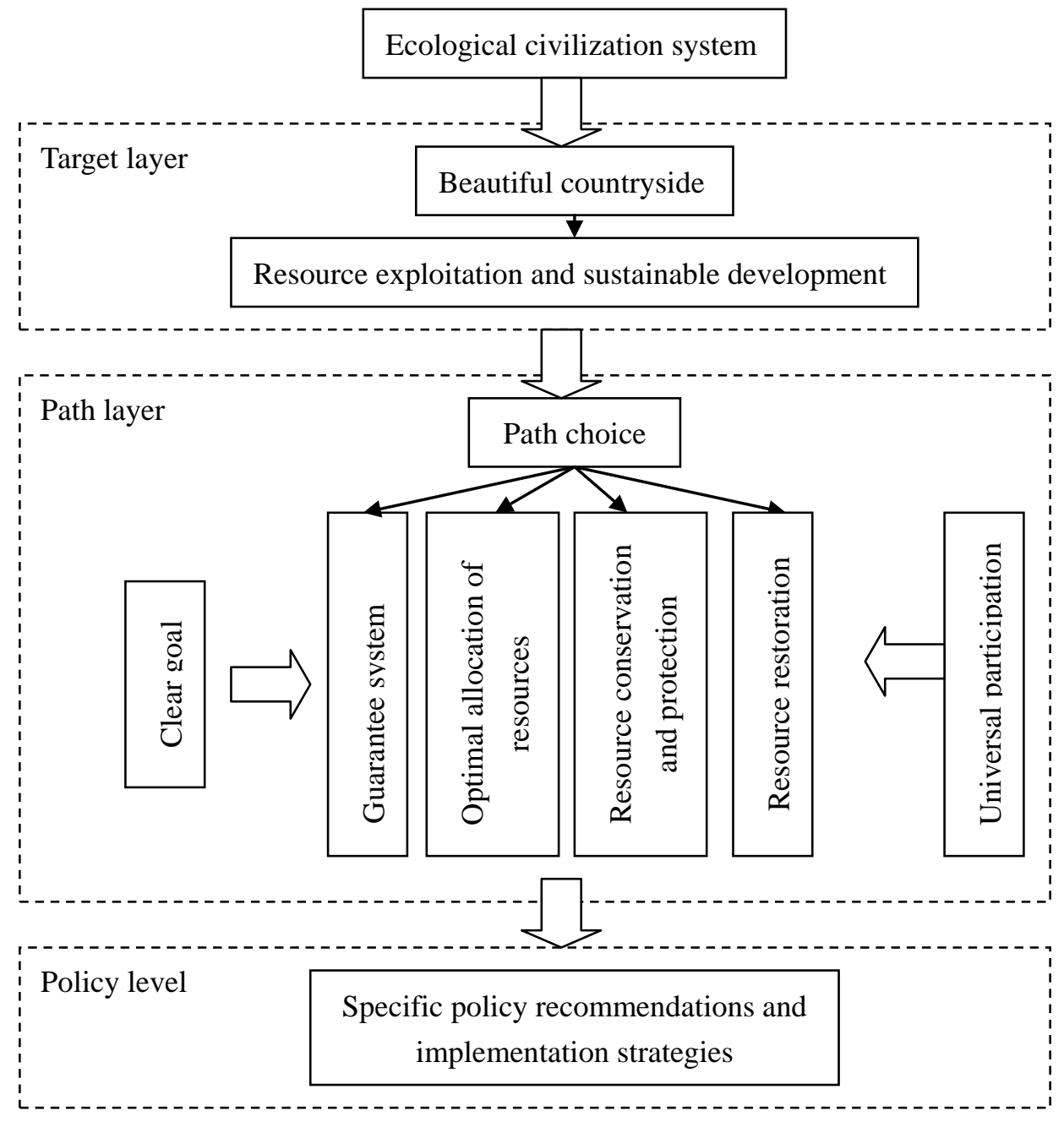

Fig.1 Ecological civilization architecture

\section{Problems in the development of Rural Ecotourism}

\section{(1) Lack of understanding of the rural eco-tourism construction}

It is a new topic in the new era that lack of understanding of the rural eco-tourism construction, a series of discussions and researches on this topic have achieved certain results. However, due to the backwardness of rural education, the popularity of the Internet and information technology is not high, the rural ecological concept and the development of the industry has brought great obstacles. Under the background of agricultural modernization and the development of township economy, the way of " developing first and harnessing later" has been adopted, this way takes the development as the precondition, do not care about the ecological environment, often led to the economy up, the environment is seriously damaged. In addition, the agricultural production in our country is based on the family as a unit of small-scale farmers, there is no collective production of the environment, so that farmers are only interested in their own interests, there is no public awareness of environmental protection. There is a more important, the local township government in the promotion of ecological industry, too much emphasis on technology, but neglect to farmers' ecological civilization knowledge guidance and education, the comprehensive benefits of eco tourism industry in the country can not reach the expected value.

(2) Rural eco-tourism industry project selection is difficult 
Because farmers have strong herd mentality, only pay attention to the current hot money, so many projects, often blindly follow the trend of the selection of projects, so easily lead to overcapacity in some projects, thus the oversupply of the embarrassing situation, affecting the project proceeds. In contrast, because people have to follow the trend to do popular projects on the market, and some relatively unpopular, but with the market potential of rural tourism projects have not developed. In addition, farmers' own level of knowledge has certain limitations, it is difficult to stand at a high level to grasp the various travel details of the project, the advanced ecological project for some differences and their traditional way of life, they are excluded, so this kind of projects are difficult to develop.

(3) Lack of patience in the construction of rural eco-tourism industry

The rural eco tourism industry is a systemic project, from planning to implementation, and then from the mid is extended to form a formal pattern of industrialization construction, which generally require a longer period of time, compared with some traditional production, it needs more time, energy and money. Farmers generally hope that through their own farming, in the short term to get income. Therefore, they often give up the rural eco-tourism industry investment, and choose to be able to harvest in the short term. It can not combine agriculture and modernization, and can not achieve sustainable development for this lack of patience in the construction of rural eco-tourism industry and abandoning the construction of advanced eco-tourism projects.

(4) The fond demand of rural eco-tourism industry construction is big

The rural eco tourism industry is a complex engineering system, which has great economic considerations for both the government and farmers. Pre investment, it is impossible to rely solely on unilateral investment of farmers, can be a certain degree of access to government or bank loan support. However, the bank loans are limited, the threshold is higher, because of the lack of cultural knowledge of farmers, the ability to understand low, often easy to lose the opportunity to borrow. These farmers who can't get a bank loan and can't afford it, although the development of rural eco-tourism projects, but they can not get the opportunity to play, so there is no way to promote the development of rural eco-tourism industry.

\section{Development strategy of rural eco tourism based on Ecological Civilization}

(1) Adopt the centralized management mechanism, realize the development of point, line and surface

The development of rural eco-tourism has many disadvantages, such as large number of projects, small scale and large dispersion, therefore, the operating mechanism can adopt the centralized management, from the point to the line, from the first to the large scale development. First of all, we can set up a tourism Regulatory Commission in the focus of eco-tourism management, carry out a series of rural ecological tourism industry organization, propaganda work, provide services for the tourism industry, improve the competitive mechanism of the local tourism industry, and strive to achieve centralized management, sustainable development of rural ecological tourism. Secondly, the government is the dominant force of the new industry, the government should play its role to the maximum, by focusing on the overall planning and arrangement of ecological tourism development, strengthen macro-control efforts to avoid the herd and blindness of tourism development. At the same time, the government should provide ecological tourism projects related to the welfare policy, support the development of rural tourism industry; through the aspects of financing, expand diversified investment pattern and mechanism of the development of rural tourism industry to form a comprehensive, multi perspective, the development of the tourism industry.

(2) Protection of resources and environment, promote the green development of Tourism 
Natural resources and environment is the core foundation of rural tourism industry's survival and development, it is the coordination aspects of interest demand, therefore, we must realize the sustainable development of tourism, under the premise of protecting the resources and environment. Whether tourism developers, farmers or tourists should take the initiative to protect rural resources and the environment. At the same time, we should realize the synchronous development of the tourism industry and the protection of resources and environment, while preventing the destructive development and the excessive waste of resources. In addition to the effective protection of water and soil, but also a series of resources and environmental protection strategies should be specified to restrict the behavior of practitioners and tourists, to maximize the protection of resources and environment. In addition, we should strengthen the protection of rural culture, coordinate the development of rural culture and tourism industry, to ensure that the tourism industry "localization" and "rural" and other ecological characteristics.

(3) Strengthen the education of ecological consciousness, improve the quality of farmers and tourists

Rural tourism project is to provide visitors with the opportunity to understand the local cultural characteristics, close to nature, Tourists should be aware of the importance of protecting the environment while enjoying mountain, flowers and insects and feeling the special folk culture. In addition, tourists and farmers are the main force of rural tourism industry, therefore, not only to ensure that the interests of the industry, also should strengthen the cultivation of man and nature, man and society and between people and harmony consciousness, cultivate the consciousness of protect the environment. Therefore, in the rural tourism industry, we should arrange to protect the ecological environment of the importance of the project, guide the tourists green consumption concept, while playing, improve their overall quality.

(4) Give full play to local advantages and build tourism brand

"Localization" and "rural" and other ecological characteristics of the rural tourism is the key to attract different geographical and ethnic characteristics of the direction of the development of a larger difference, such as the humanities and natural scenery. With the improvement of living standards, a single agricultural tourism (crop picking, farmhouse) can not meet the long-term healthy development of rural tourism industry. The countryside has a unique cultural customs and rich local concepts, therefore, in the development of tourism projects, we should pay attention to the spiritual reaction of rural farmers digging cultural connotation, take characteristic development road combined with the local tourism advantages, outstand tourism of "local characteristics", build the unique tourism products, and ensure the uniqueness and attractiveness of tourism industry.

\section{Conclusion}

Starting with the importance of the ecological civilization development, in this paper, the present situation of rural eco-tourism has been analyzed, it makes a deep analysis of the problems existing in the development of rural eco-tourism, and put forward many development strategies that the centralized operation mechanism, development and Realization of dot, protection of resources and the environment, advocate green tourism development, strengthen ecological consciousness education, improve the quality of farmers and tourists as well as local advantage, build tourism brand and so on, which has certain significance to promote ecological civilization and sustainable development of rural tourism industry. 


\section{Acknowledgement}

The work was supported by the the National Social Science Foundation of China with the project number 2015CMZ027 and the project name Study on the Ways and Effects of the Integration of Tourism Industry and Cultural Industry in the Multi-ethnic Tibetan Plateau Region.

\section{Reference}

[1] Xia Xiuhe. Study on the development model of Rural Ecotourism in Kunming [D]. Yunnan University of Finance and Economics, (2016)

[2] Liu Lei. Study on the sustainable development of rural tourism based on tourism seasonality [D]. Guangxi Normal University, (2016)

[3] Wei Wei. Analysis of the modern rural ecotourism development [J]. Art Education Research, Vol.22, (2014), p.33

[4] Liu Xiuli. The development of rural tourism with the idea of ecological civilization [J]. Contemporary Economics, Vol.17, (2014), p.30-31.

[5] Shi Songjie. Study on the sustainable development of rural tourism in China from the perspective of ecological civilization[D]. Chengdu University of Technology, (2014)

[6] Sun Yihui. Study on rural tourism landscape planning and design under the perspective of ecological civilization [D]. Zhejiang Agriculture and Forestry University, (2013)

[7] Zheng Yaoxing, Liu Guoping, Zhang Feifei. Thinking on the transformation and upgrading of rural tourism in Fujian from the perspective of ecological civilization [J]. Guangdong Agricultural Sciences, No.07, (2013), p.211-214, 222.

[8] Bao Wenjuan. Study on the development model of Rural Ecotourism in Sichuan earthquake area [D]. Southwest Jiao Tong University, (2011)

[9] Lan Zongbao, Wei Liping, Lu Yuming. Study on sustainable development strategy of rural tourism under the concept of ecological civilization [J]. Guangdong Agricultural Sciences, No.01, (2011), p. 223-225.

[10] Liu Jingyi. Development of rural ecotourism and its model [D]. Fujian Agriculture And Forestry University, (2010)

[11] Su Na. Jiangxi eco-tourism co-petition research from the perspective of ecological civilization —in the case of wuyuan and yaoli [D]. Jiangxi Normal University, (2009)

[12] Xiang Pinhui. Study on the linkage development model of scenic spots and Rural Ecotourism [D].Zhejiang University, (2008)

[13] He Xiaofang. Study on rural ecotourism planning method [D]. Zhejiang University, (2005) 